\title{
The Grid Joint Optimization Control Strategy with the Double- Fed Induction Generator
}

\author{
Xinyu Liu, Huili Yang and Ke Bai \\ School of electric power \\ North China University of Water Resource and Electric power, Zhengzhou, \\ 450011, China \\ lxy22101@163.com
}

\begin{abstract}
Aiming at the grid-connected problems of the double-fed induction generator (DFIG), this paper researches the control technology of the rotor excitation and the pitch angle and proposes a grid-connected DFIG joint optimization control strategy of the rotor excitation and the pitch angle based on the structure decentralized theory, and establishes the joint optimization model of the grid-connected DFIG. On the basis of the model, the rotor excitation current adaptive terminal sliding mode controller and the pitch angle controller are designed. The simulation results show that the proposed control strategy can achieve an effective control of the DFIG's power angle and the $D F I G$ 's rotor flux and reduce the adverse effects of the power angle when the double-fed wind generator and synchronous generator $(S G)$ are in parallel operation. The algorithm given by this article not only improves the system's ability to resist external disturbances, but also enhances the transient stability of the power system. It has important actual significance and practical application value.
\end{abstract}

Keywords: DFIG, Grid-connected, Decentralized structure, Adaptive, Sliding mode control

\section{Introduction}

When the power system is disturbed, the wind farm will have a greater impact on the transient stability of the grid after the synchronization of the wind power. The domestic and foreign scholars have done a lot of research work and have made some progress on the interaction between the synchronization of the wind power and the grid, but these achievements are effective in the wind power gridconnected certain aspects and difficult to ensure their versatility. In the literature [1], the compared simulation studies are carried on between the doubly-fed induction generator (DFIG) and the traditional squirrel cage generators, and the conclusion is drawn that the synchronization of the wind power can improve the system transient stability, however, the paper does not analyze the interaction of the DFIG and the conventional synchronous motor (SG). Literature [2] analyzes the problems of the conventional SG and the DFIG "bundling" for long-distance transmission, the simulation results show that the synchronization of the wind power does not affect the stability of the system. Literature [3] considers that the wind power will increase damping of the power system and can help to enhance the anti-interference ability of the system. Literature [4] considers that the total mechanical inertia of the system is reduced, which reduces the ability of the system to resist large external disturbances after the synchronization of the DFIG. Literature [5] carries out a more detailed study on the power system containing wind farm and points out that when the DFIG and SG with the same capacity are 
connected into the same power system at the same access points, the former is more conducive to enhance the transient stability of power systems.

Through analyzing the above literatures, the domestic and foreign scholars have not reached the same conclusions on the DFIG grid-connected influence on the stability of the power system. The main reason is that the researchers use the different modeling methods and control strategies. Therefore, this paper focuses on the basic and network operation model of the DFIG and analyzes the transient stability of the system after the synchronization of the wind power by fully considering the dynamics of the rotor flux and regulation of the active and reactive power of the pitch angle. On the basis, this paper proposes the strategy of the adaptive terminal sliding mode control of the rotor flux and the wind turbine pitch angle joint optimization control. The system with this control strategy has achieved the effective control of the DFIG grid-connected.

\section{The Interaction Mechanism Analysis Of The DFIG And The Grid}

Since the stator of the doubly-fed induction generator is connected directly to the grid, so it must have the electromagnetic relation with the synchronous motor and its transient characteristics have more or less impact on the stability of the synchronized [6]. Similarly, when the fault of the power system occurs, it will also adversely affect the doubly fed induction generator.

\subsection{The Effect of Dynamic Characteristics of the Power Angle on the Grid}

Figure 1 shows the main wiring diagram of the Wind \& Fire hybrid transmission. According to the literature [7], when the open circuit fault occurs in a loop, the electromagnetic power expression of the synchronous generator SG can be written as:

$$
P_{e}=\frac{E_{s}^{2}}{x_{11}}+\frac{E_{s} U}{x_{12}} \sin \delta_{s}+\frac{E_{s} E_{d}}{x_{13}} \sin \left(\delta_{s}-\delta_{d}\right)
$$

Where $E_{s}$ and $E_{d}$ denote the SG's and DFIG's inner potential respectively, $\mathrm{U}$ is the voltage on the infinite bus and is assumed a constant, $\delta_{s}$ and $\delta_{d}$ are respectively the power angle of the SG and DFIG; $x_{11}$ and $x_{12}$ are the self -impedance during the fault, $x_{13}$ is the transfer reactance during the fault.

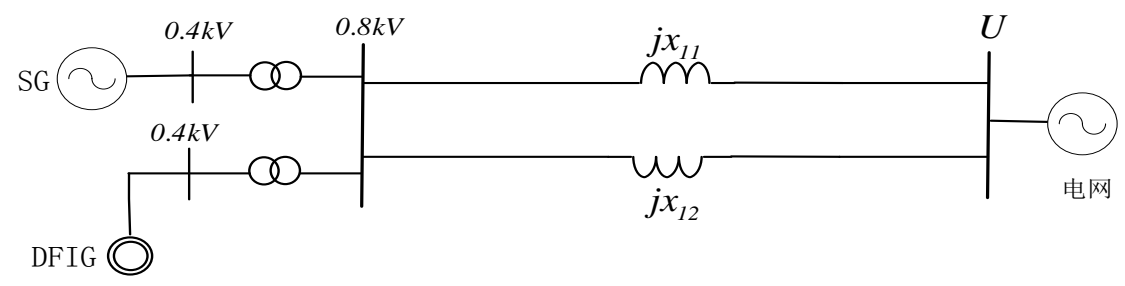

\section{Figure 1: The Main Wiring Diagram Of The Wind \& Fire Hybrid Transmission}

For the compositions of the formula (1), the item 3 can best embody the interactions between the DFIG and the SG. The variation of electromagnetic power which caused by item 3 includes the following three cases:

(1) If the power angle curve $\delta_{s}$ and $\delta_{d}$ are parallel, then $P_{e}$ remains unchanged;

(2) If power angle curves $\delta_{s}$ and $\delta_{d}$ intersect and the change rate of the former is 
greater than the latter, then $P_{e}$ continues to increase;

(3) If power angle curves $\delta_{s}$ and $\delta_{d}$ intersect and the change rate of the latter is greater than the former, then $P_{e}$ continues to reduce;

Based on the above, taking the case (1) as a reference, for the case of (3), according to the relationship between the electromagnetic power and torque, the SG electromagnetic power becomes smaller due to the large acceleration torque. The result is not conducive to the stability of the SG first swing and the system transient stability deteriorates; for the case (2), the electromagnetic power of the SG is larger than the original, which causes acceleration torque smaller. Then the result is in favor of the stability of the SG first swing and the system transient stability becomes stronger.

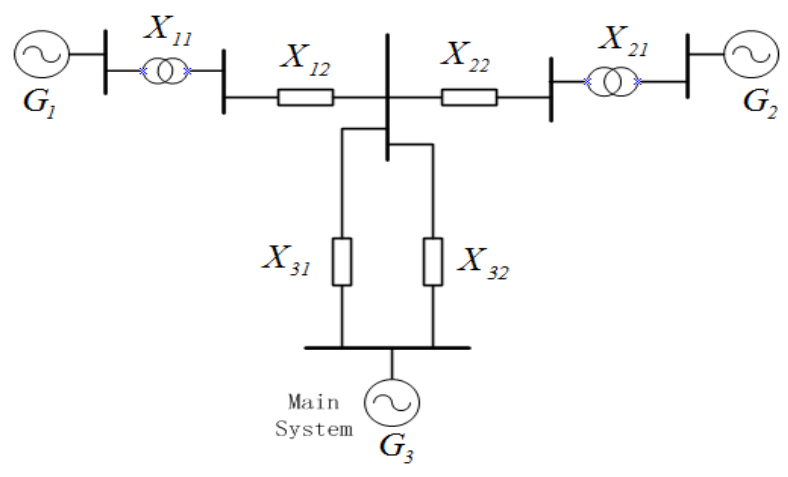

Figure 2: The System Simulation Diagram

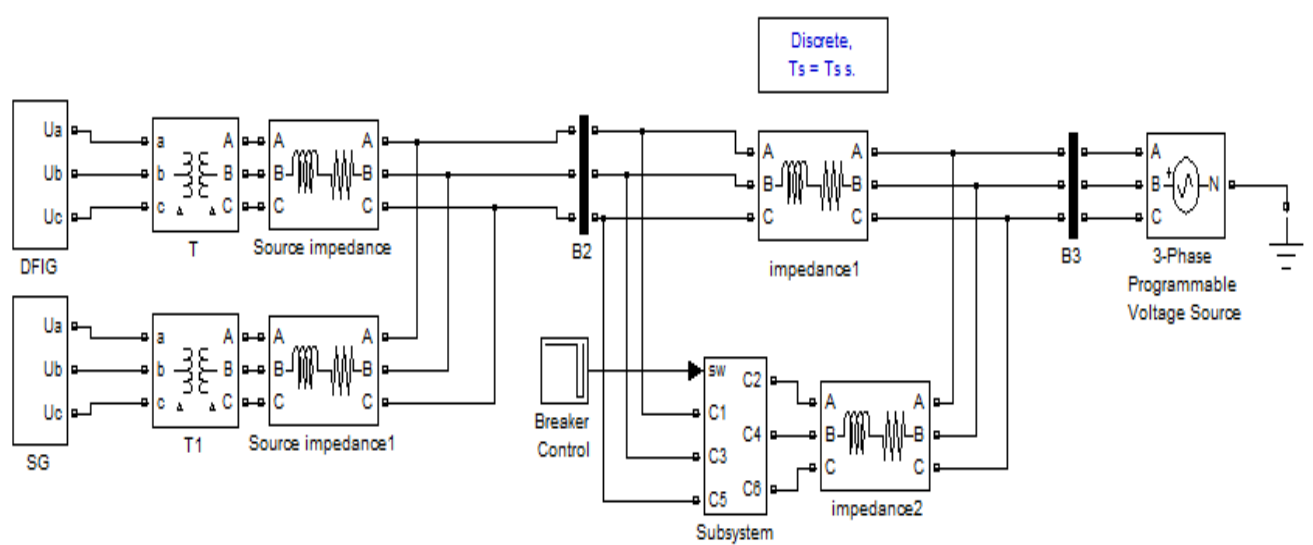

Figure 3: The System Simulation Model Diagram

In order to further prove the effect of the DFIG on the power system stability, the simulation system is established as shown in Figure 2. It corresponds to the simulation model shown in Figure 3. The simulation parameters are as follows:

Equivalent parameters of the doubly-fed generator: Rated power $P_{N}=6 \mathrm{MW}$, Rated voltage $U_{N}=690 \mathrm{~V}$, Rated frequency $f_{N}=50 \mathrm{HZ}$, Synchronous speed $n_{N}=1500 \mathrm{r} / \mathrm{min}$, Stator resistance $R_{s}=0.008 \Omega$, Rotor resistance $R_{r}=0.0019 \Omega$ ( The stator side conversion value), Stator inductance $L_{s}=0.2 \mathrm{mH}$, Rotor inductance $L_{r}=0.547 \mathrm{mH}$ ( The stator side conversion value), Mutual $L_{m}=15.66 \mathrm{mH}$ (The stator side conversion value).

The equivalent parameters of the Synchronous generator: Rated power $P_{N}=5 \mathrm{MW}$, Rated voltage $U_{N}=690 \mathrm{~V}$, Rated frequency $f_{N}=50 \mathrm{HZ}$, Stator resistance $R_{s}=0.00076 \Omega$, 
Excitation resistance $R_{f}=0.000173 \Omega$, Stator Inductance $L_{s}=1.123 \mathrm{e}-005 H$.

Network parameters $X_{T}=j 52.6 \Omega, Z_{1}=Z_{2}=(15+j 112.7)$.

Here are two cases to illustrate the DFIG impact on the stability of the power system:

(1) G1 and G2 are synchronous generator, which composed of conventional transmission systems together with the main system G3 via the long-distance transmission;

(2) G1 and G2 are respectively the doubly-fed induction generator and the synchronous generator, which composed of a "Wind \& Fire" hybrid transmission system through long-distance transmission together with the main system G3.

So the conventional transmission system can be taken as a reference to study the stability of the "Wind \& Fire" hybrid transmission system in order to provide technical reference for future similar hybrid transmission system. It should be noted that the capacity of the synchronous generator in the case (1) and the capacity of the doubly fed induction generator in the case (2) are the same. The system fault set as follows: when $\mathrm{t}=1 \mathrm{~s}$, the double-circuit transmission lines $\mathrm{X} 31$ and $\mathrm{X} 32$ break one circuit; when $\mathrm{t}=1.2 \mathrm{~s}$, the system returns to normal.

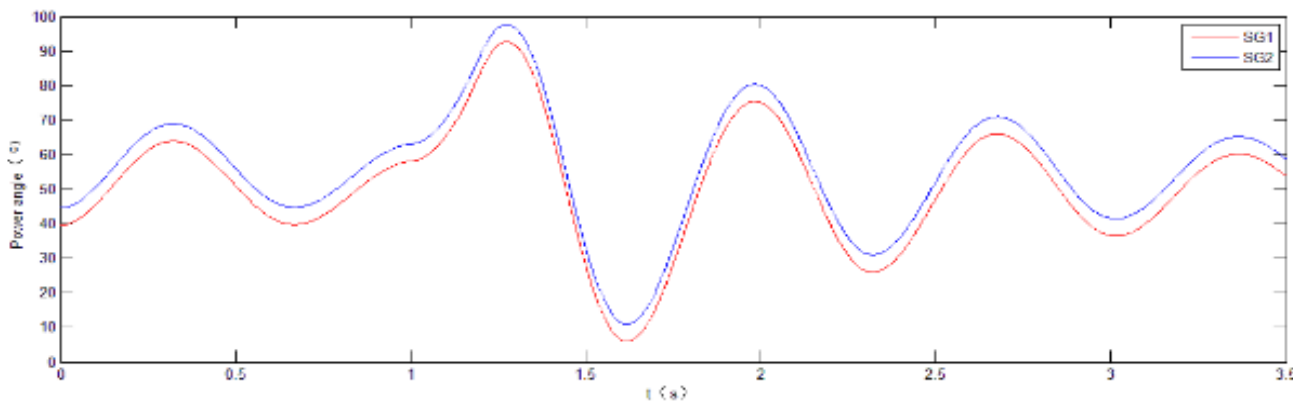

Figure 4. The Power Angle Curve Of Two Synchronous Motors Running Parallel

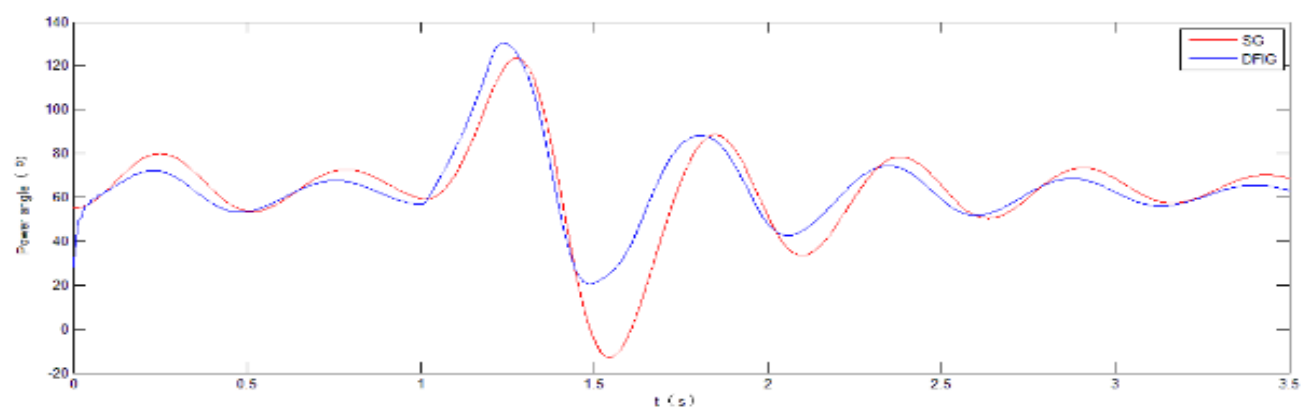

Figure 5: The Power Angle Curve Of The DFIG Parallel Running With The SG

Figures 4 and 5 respectively show the power angle curve of the SG and the DFIG in both cases. It can be seen from the figure that when G1 and G2 are both synchronous generator and in parallel operation, the power angle curve has the homology and doesn't intersect. In this case the maximum power angle of the G1 and G2 is $98^{\circ}$. But when the doubly-fed induction generator G1 and the synchronous generator G2 runs in parallel, the curve of their power angle appears the crossing. When a fault occurs, the power angle of the doubly fed induction generator increases rapidly and then the power angle of the adjacent synchronous generator increases together, which makes the maximum power angle of the synchronous generator up to $120^{\circ}$. These two cases shows that, for the "Wind \& Fire" hybrid transmission system, when the grid fails, on the one hand the fault would have an adverse effect on the doubly fed induction generator, on the other 
hand the doubly fed induction generator produce interaction adversely on the adjacent synchronous generator which woken the stability of the system.

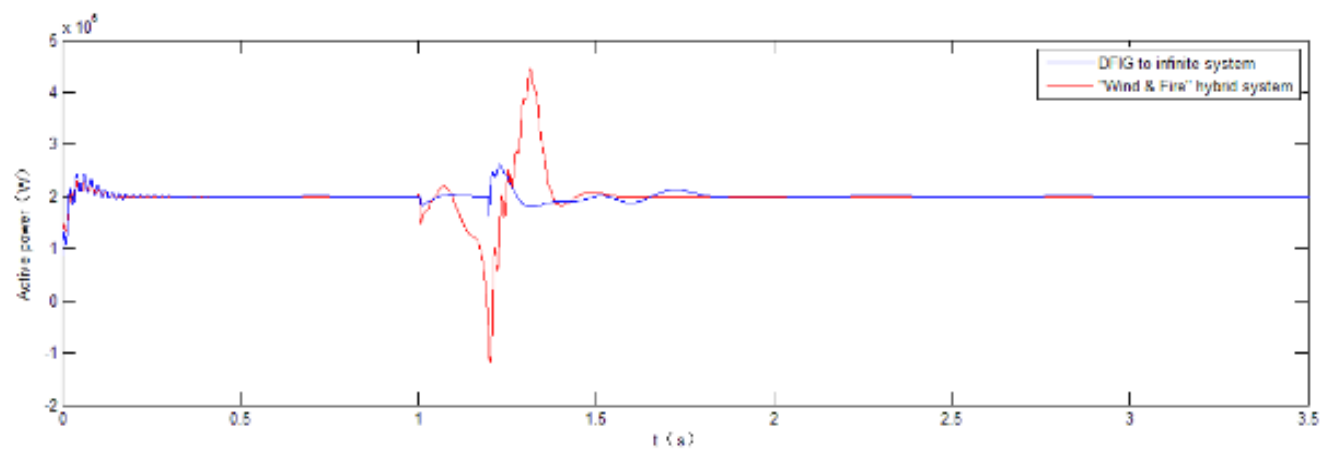

Figure 6: The Contrast Curve of the DFIG's Output Active

Figure 6 illustrates that when a fault occurs in the hybrid transmission system, though the mutation of the power angle of the DFIG caused a temporary power oscillation of the DFIG, but the rapid recovery characteristic of its power allows the active power return to normal in a short time, thus the active power output almost unchanged during the fault, which made the output of the synchronous generator begin to decrease and caused a rapid increase of the power angle of the SG in order to increase the output power of the synchronous generator. These cases resulted in the active oscillation of the SG and reduced the grid stability.

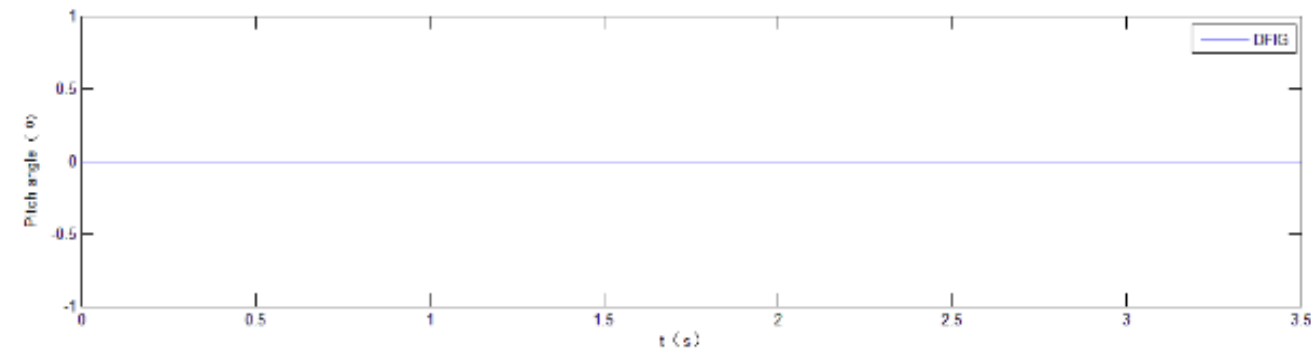

Figure 7: The DFIG's Pitch Angle Curve of the Wind \& Fire Hybrid System

Figure 7 shows the pitch angle curve of a paddle DFIG wind turbine in the Wind \& Fire hybrid transmission system. As can be seen from the figure, when the grid fails, in order to get the maximum power, the pitch angle of the wind turbine is always maintained at $0^{\circ}$ and does not react due to grid failure. Thus, the fast recovery characteristics of the active output of the DFIG makes the active output of the SG reduce accordingly and the Synchronous generator rotor begin to accelerate. This case caused the output power oscillation of the synchronous generator and woken the stability of the power system.

\subsection{Grid Failure Impact On The Dynamic Characteristic Of The DFIG}

To analyze the effect of grid failure on the DFIG, Figure 8 shows the phase diagram of the inner potential $\dot{E}$, terminal voltage $\dot{V}_{g}$ and the power angles $\delta^{[8]}$. Where $x_{I}$ is the internal reactance, $x_{E}$ is the external reactance, $I$ is the stator current. Under the normal operation status of the system, the power angle $\delta$ of the DFIG is smaller, the terminal voltage $V_{g}$ and the stator current $I$ keep ratings unchanged. After the failure, the 
DFIG power angle changes drastically and its value increases rapidly to $\delta^{\prime}$. In the closed-loop control strategy of the power, the stator current also increases to $I^{\prime}$, resulting in terminal voltage down to $V_{g}^{\prime}$. In other words, the grid failure causes mutations of the DFIG power angle, and dramatic changes of the power angle have led to over-current of the rotor and drops of the terminal voltage.

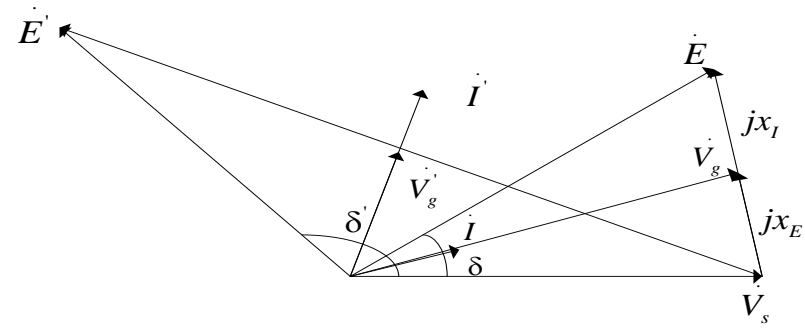

Figure 8: Relationship Phase Diagram of the $\dot{E} 、 \dot{V}_{g}$ And $\delta$

In order to further verify the influence of the grid fault on the doubly fed induction generation, this paper redone simulation experiments of the 2.1 section, assuming that a single fault occurs when $t=3.0 \mathrm{~s}$ and the system is back to normal when $t=3.2 \mathrm{~s}$. The response curve of the terminal voltage and the response curve of the DFIG's rotor current are shown in figure 9 and figure 10 respectively when the measured power angle changes.

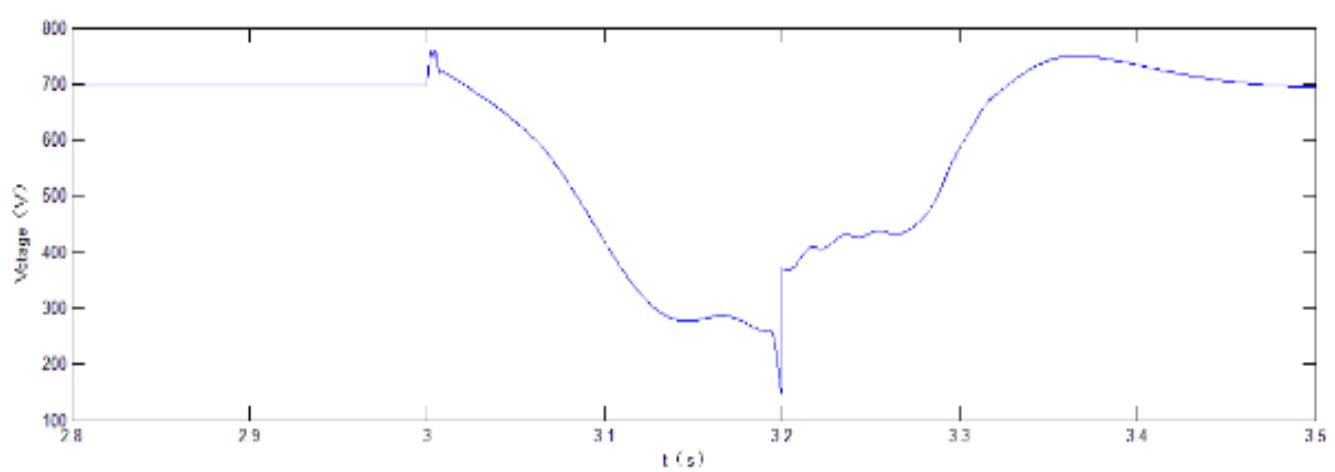

Figure 9: Terminal Voltage Drop Caused By The Drastic Changes In Power Angle

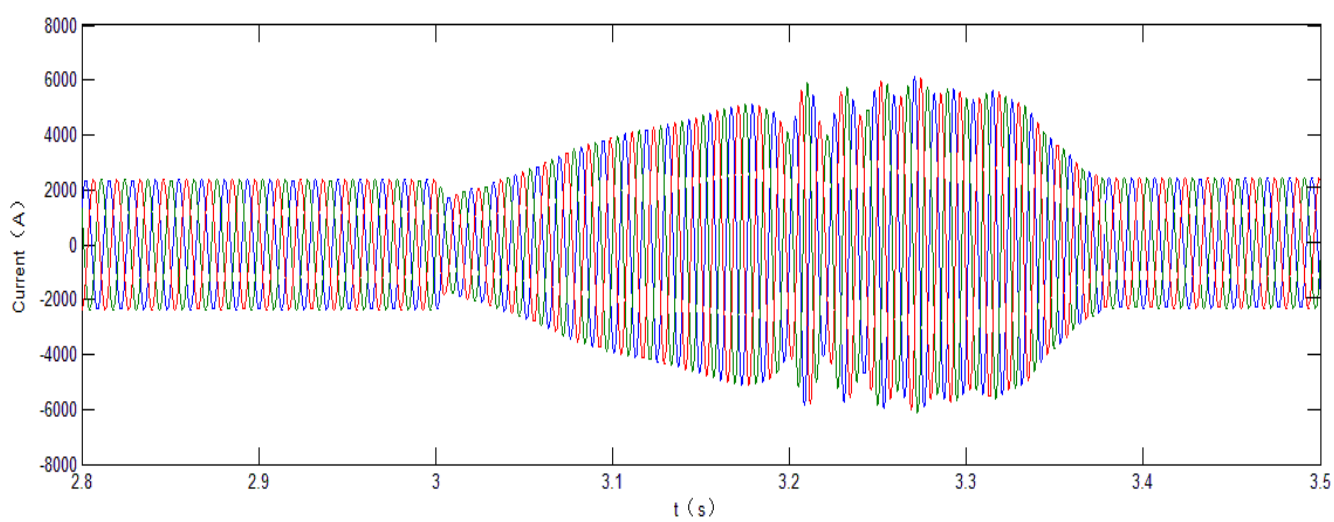

Figure 10: Rotor Overcurrent Caused By The Upheaval Of The Power Angle 
From figure 9 and figure 10, it can be seen that when the power angle of the DFIG changes dramatically, its terminal voltage drops rapidly and the minimum voltage of the terminal voltage is reduced to $20 \%$ of the original. Along with the rapid decline of the terminal voltage, the DFIG's rotor appears serious over-current phenomenon and the maximum of the current up to three times the normal value.

In summary, when the grid fails, with the conventional PI control strategy, disturbances may cause serious effects on the DFIG, which is the reason that the DFIG frequent off network.

\section{The Optimization Control Strategy of the DFIG Grid-Connected}

Through the analysis of the synchronization of the DFIG, it found that in the case of grid failure, not only the output power of the synchronous generator occurs oscillations and the system stability become poor, but also cause the terminal voltage of the doublyfed induction generator to reduce or rotor overcurrent when the double-fed wind power generator and synchronous generator operate in parallel. These negative factors are related with the characteristics of the DFIG's rotor flux on the one hand and on the other hand also are related with the regulation of its pitch angle. Therefore, if the traditional control strategy of the inverter and pitch angle can be improve, when the disturbance of the power system occurs, the power angle of the DFIG can be little changed or no changed, and the pitch angle can be adjusted in real time, then the stability of the power system can be enhanced at the same time. The phenomenon of the DFIG's own terminal voltage drops or rotor over-current can also be resolved at last.

\subsection{The DFIG Rotor Flux Control Strategy Design}

According to literature [9], the dynamic equation of the DFIG rotor flux is:

$$
\left\{\begin{array}{l}
\dot{\Psi}_{d r}=-\frac{L_{s} R_{r}}{L_{s} L_{r}-L_{m}^{2}} \Psi_{d r}+\omega_{s} \Psi_{q r}+u_{d r} \\
\dot{\Psi}_{q r}=-\frac{L_{s} R_{r}}{L_{s} L_{r}-L_{m}^{2}} \psi_{q r}-\omega_{s} \Psi_{d r}+u_{q r}+\frac{R_{r} L_{m} U_{S}}{\omega_{l}\left(L_{s} L_{r}-L_{m}^{2}\right)}
\end{array}\right.
$$

According to equation (2), when power is in generating operation, the relationship structure between the external voltage which is applied by the inverter on the rotor and the rotor flux is shown in Figure 11.

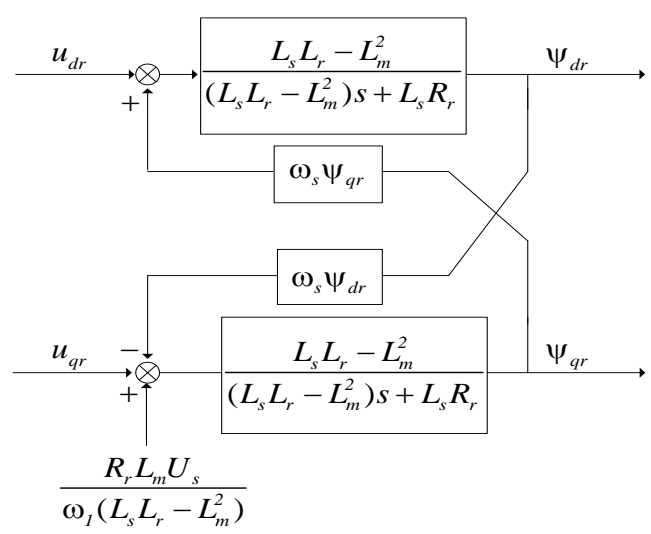

Figure 11: The Relationship Graph between Applied Voltage Of The DFIG
Rotor And The Flux

Through the analysis of figure 11 , when the DFIG is in generating operation, the 
controlled outputs of the system which is to be control are the rotor flux $\psi_{d r}$ and $\psi_{q r}$ of the DFIG's, control inputs are the rotor voltage $u_{d r}$ and $u_{q r}$. Therefore, the controller of the rotor flux system of the DFIG can be designed and the rotor flux control of the generator can be achieved also.

When the DFIG and SG are in parallel operation, if the rotor flux components is fully self-adaptive to the disturbance caused by the power network fault, the power angle of the DFIG can be not affected by the disturbance in order to prevent the power-angle mutant during the faults, this requirement may be achieved by using the method of sliding mode control. Thus, equation (2) can be written in the form of the following state-space equation (3).

$$
\dot{Z}=A Z+B U+F
$$

Where $F$ represents a disturbance caused by a grid failure, $Z=\left[\begin{array}{c}z_{11} \\ z_{21}\end{array}\right]$ is State variable, $U=\left[\begin{array}{c}z_{10} \\ z_{20}\end{array}\right]$ is control input, $Z_{11}$ represents a rotor d-axis flux $\psi_{d r}$, $Z_{21}$ represents a rotor q-axis flux $\psi_{q r}, Z_{10}$ represents a d-axis current control signal $u_{d r}$ of the rotor, $Z_{20}$ represents a q-axis current control signal $u_{q r}$ of the rotor.

$$
\begin{gathered}
A=\left[\begin{array}{cc}
-\frac{L_{s} R_{r}}{L_{s} L_{r}-L_{m}^{2}} & \omega_{s} \\
-\frac{L_{s} R_{r}}{L_{s} L_{r}-L_{m}^{2}} & -\omega_{s}
\end{array}\right] \\
B=\left[\begin{array}{ll}
1 & 0 \\
0 & 1
\end{array}\right] \\
F=\left[\begin{array}{l}
0 \\
f
\end{array}\right] \\
f=\frac{R_{r} L_{m} U_{s}}{\omega_{l}\left(L_{s} L_{r}-L_{m}^{2}\right)}
\end{gathered}
$$

Easy to prove that: $\operatorname{rank}\left[\begin{array}{ll}B & F\end{array}\right]=\operatorname{rank}[B]=2$

According to the equation (4), the sliding mode of the double-fed wind power generation system meets the necessary and sufficient conditions ${ }^{[10,11]}$ which are immune to the outside interference. Therefore, the doubly-fed wind turbine has completely robustness to the disturbance caused by the power grid fault and the sliding mode is not affected by power grid failure by designing a suitable sliding mode controller.

Define the system state variables is error of the rotor q-axis flux and its given value eq $=\mathrm{z}_{21}{ }^{*}-\mathrm{Z}_{21}$, according to equation (2), the error state equation of the q-axis flux of the DFIG can be written as: 


$$
\dot{e_{q}}=\omega_{s} z_{21}^{*}-\omega_{s} e_{q}-z_{20}+\dot{z}_{2 l}^{*}+F_{q}
$$

Where $F_{q}=\left(\frac{L_{s} R_{r}}{L_{s} L_{r}-L_{m}^{2}} z_{11}-f\right)$ represents a disturbance caused by the grid fault.

Based on the above, the paper proposes the following integral sliding surface

$$
s_{q}=k_{p q} e_{q}+k_{i q} \int_{o}^{t} e_{q}^{p / q} d \tau
$$

Where $k_{p q}$ and $k_{i q}$ are respectively proportional and integral factor, and they are greater than zero. In Equation (6) the proportional used to accelerate the dynamic response of the system to track, the integral term is used to eliminate the steady state error of the system. Therefore, with the PI integral sliding hyper surface, changing the value of $k_{p q}$ and $k_{i q}$ can change the dynamic characteristics of the sliding surface.

According to the proposed terminal mold surface, if the disturbance $\mathrm{Fq}$ is bounded, which meet $\left|F_{q}\right| \leq \frac{k}{k_{p q}}$, where $\mathrm{k}$ is a constant greater than zero, you can get the following theorem.

Theorem If grid-connected control systems of the DFIG meet $\left|F_{q}\right| \leq \frac{k}{k_{p q}}$ and select integral terminal mold surface as equation (6), when the switching gain $\eta_{q}>\frac{k}{k_{p q}}$, use the following control law $z_{20}=-\omega_{s} e_{q}+\frac{k_{i q}}{k_{p q}} e_{q}^{p / q}+\omega_{s} z_{2 l}^{*}+\frac{\eta_{q}}{k_{p q}} \operatorname{sgn}\left(s_{q}\right)+z_{2 l}^{*}$ where $\eta_{q}$ is a constant greater than zero, then the DFIG's flux error $e$ can converge to zero in finite time and the system can be robust stability.

Proof: First prove flux error $e$ of the DFIG is convergent:

According to equation (6), the initial state of the integral term is set as follows

$$
\int_{-\infty}^{o} e_{q}^{p / q} d \tau=-\frac{k_{p q}}{k_{i q}} e_{q 0}
$$

Where $e_{q 0}$ is the initial time deviation.

At time $\mathrm{t}=0$, the formula (7) into equation (6) to get

$$
s_{q}(O)=k_{p q} e_{q O}+k_{i q} \int_{-\infty}^{t} e_{q}^{p / q}(\tau) d \tau=k_{p q} e_{q o}-k_{i q} \frac{k_{p q}}{k_{i q}} e_{q O}=O
$$

Equation (8) shows that, by choosing an appropriate initial value to meet $s_{q}(0)=0$, you can ensure that the initial state of the system is located in the sliding surface in order to improve the robustness of the system.

Equation (6) shows that when the system reaches the sliding surface, then $s_{q}=s_{q}=O$,

Namely 


$$
e_{q}=-\frac{k_{i q}}{k_{p q}} e_{q}^{p / q}
$$

The following equation can be obtained from the error state equation of the q-axis flux component of the DFIG

$$
e_{q} \frac{1}{\frac{k_{i q}}{k_{p q}} e_{q}^{p / q}}=-1
$$

Integrating simultaneously on both sides for the formula (10)

$$
\int_{e_{q}}^{0} \frac{1}{\frac{k_{i q}}{k_{p q}} e_{q}^{p / q}} d e_{q}=-\int_{0}^{\Delta t_{q}} d t
$$

The formula (10) is solved

$$
\Delta t_{q}=\frac{q k_{p q}}{k_{i q}(q-p)} e_{q}^{l-\frac{p}{q}}
$$

(12) Illustrates the tracking error of the q-axis flux component of the DFIG can converge to zero in the $\Delta t_{q}$ time.

The stability of the system is proved as following:

Select the Lyapunov function as $V=\frac{1}{2} s_{q}^{2}$, there

$$
\begin{aligned}
& \dot{V}=s_{q} \dot{s}_{q} \\
& =s_{q}\left[k_{p q}\left(\omega_{s} z_{2 l}^{*}-\omega_{s} e_{q}-z_{20}+\dot{z}_{2 l}^{*}+F_{q}\right)+k_{i q} e_{q}^{p / q}\right] \\
& =s_{q}\left(k_{p q} \omega_{s} z_{2 l}^{*}-k_{p q} \omega_{s} e_{q}-k_{p q} z_{20}+k_{p q} z_{2 l}^{*}+k_{p q} F_{q}+k_{i q} e_{q}^{p / q}\right) \\
& =s_{q}\left(-\eta_{q} \operatorname{sgn}\left(s_{q}\right)+F_{q}\right) \leq\left(-\eta_{q}\left|s_{q}\right|+F_{q}\left|s_{q}\right|\right) \leq-\left|s_{q}\right|\left(\eta_{q}-\frac{k}{k_{p q}}\right)<0
\end{aligned}
$$

Therefore, the controller of the subsystem $\Sigma_{2}$ is stable and the tracking error of the qaxis flux component converges to zero in the $\Delta t_{q}$ time.

Similarly available control law of the control subsystem $\Sigma_{1}$ of the DFIG's flux is:

$$
z_{10}=-\frac{L_{s} R_{r}}{L_{s} L_{r}-L_{m}^{2}} e_{d}+\frac{k_{i d}}{k_{p d}} e_{d}^{p / q}+\frac{L_{s} R_{r}}{L_{s} L_{r}-L_{m}^{2}} z_{l l}^{*}+\frac{\eta_{d}}{k_{p d}} \operatorname{sgn}\left(s_{d}\right)+\dot{z}_{l l}^{*}
$$

Where $\eta_{d}$ is a constant and greater than zero.

Convergence time of the tracking error of the DFIG d-axis flux component is:

$$
\Delta t_{d}=\frac{q k_{p d}}{k_{i d}(q-p)} e_{d}^{1-\frac{p}{q}}
$$


To complete the proof.

The control subsystem simulation model of the rotor q-axis flux component of the DFIG is shown in Figure 12. The control subsystem simulation model of the rotor d-axis flux component of the DFIG is shown in Figure 13.

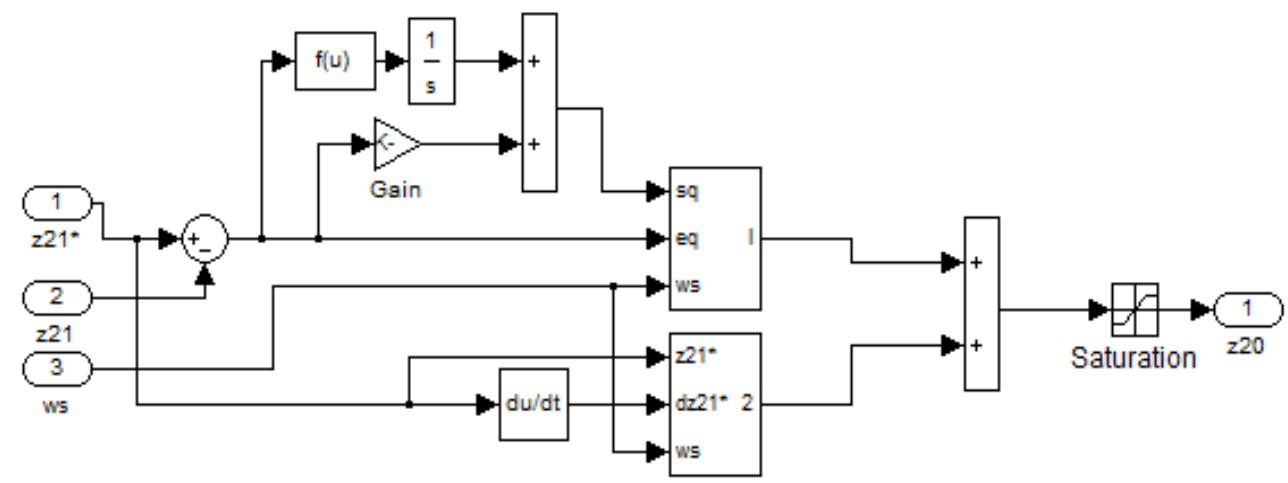

Figure 12: The Control Subsystem Simulation Model Of The Rotor Q-Axis Flux Component Of The DFIG

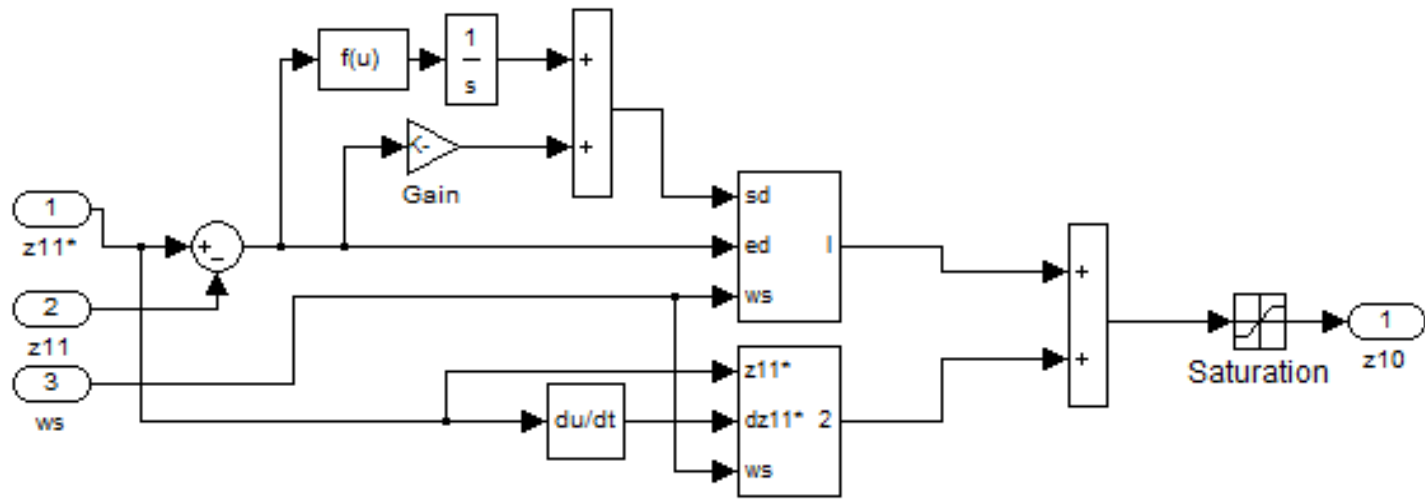

Figure 13: The Control Subsystem Simulation Model of the Rotor D-Axis Flux Component of the DFIG

When the DFIG is combined to the grid, the control block diagram of terminal sliding mode of the rotor flux is shown in Figure 14 and its simulation model is shown in Figure 15. It can be seen from the figure that the enable control link only works when the grid fails and causes the upheaval of the DFIG's rotor flux. It does not work when the system is in normal operation additional. So that the expression of the enable control link is:

$$
\left\{\begin{array}{l}
u_{\psi d r}^{*}=u_{\psi d r} \operatorname{sgn}\left(\left|\psi_{d r}^{*}-\psi_{d r}\right|\right) \\
u_{\psi q r}^{*}=u_{\psi q r} \operatorname{sgn}\left(\left|\psi_{q r}^{*}-\psi_{q r}\right|\right)
\end{array}\right.
$$




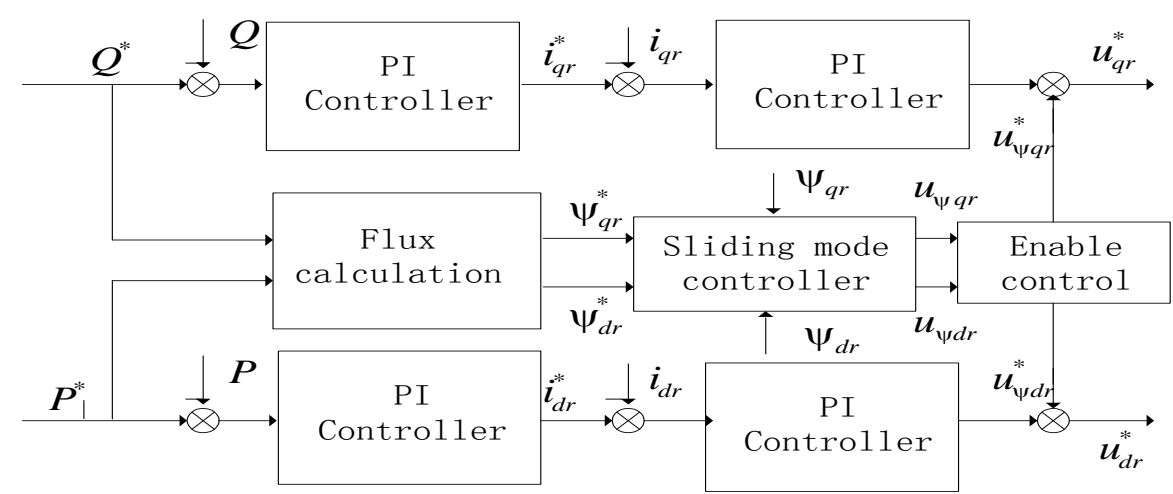

\section{Figure 14: The Control Block Diagram Of Terminal Sliding Mode Of The DFIG's Flux}

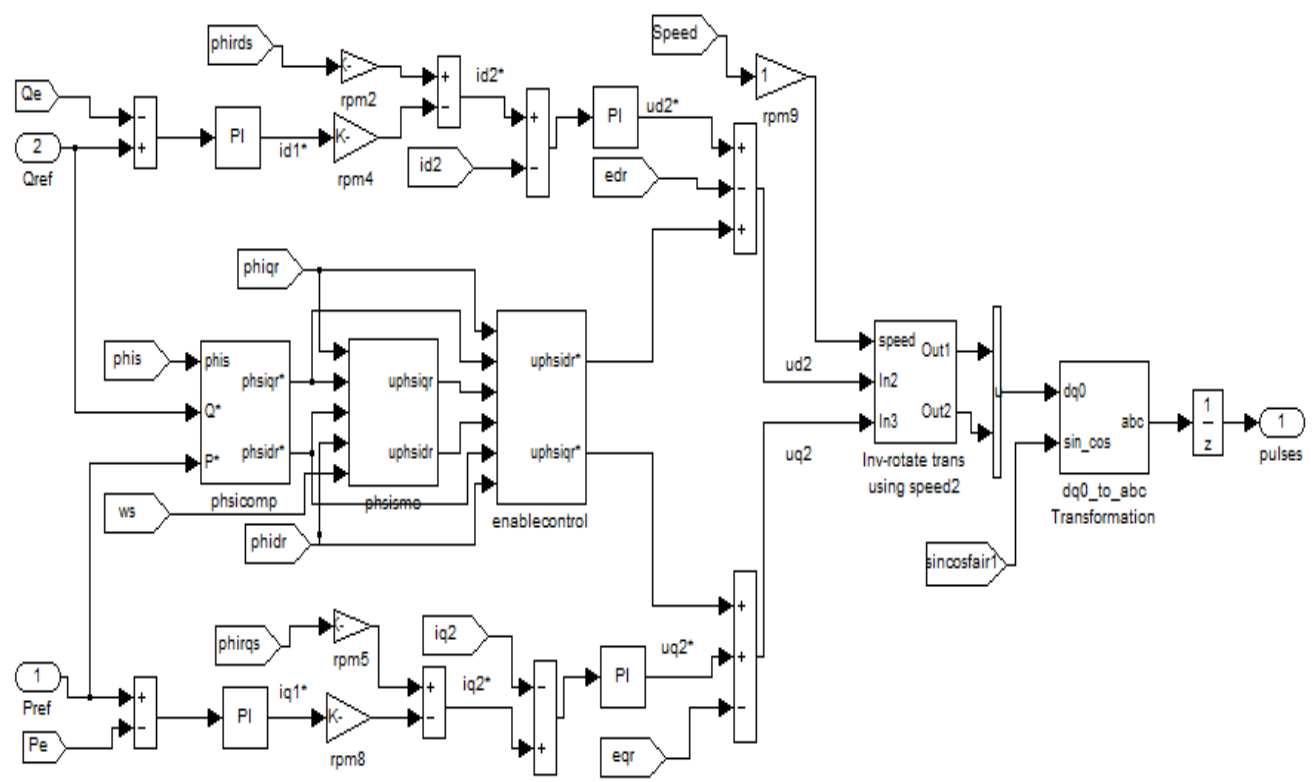

Figure 15: The Control Simulation Model of Terminal Sliding Mode of the DFIG's Flux

From the figure 16 , the command value $\psi_{q r}^{*}$ and $\psi_{d r}^{*}$ of the rotor flux component can be calculated according to the given value of the active and reactive power and the equation (2); By real-time computing links of the flux, the flux feedback value $\psi_{d r}$ and $\psi_{q r}$ can be calculated; Through sliding mode controller of the rotor flux, the additional control signals $u_{\psi d r}^{*}$ and $u_{\psi q r}^{*}$ of the inverter are exported. The flux additional control signal only works when the grid produces disturbance due to a fault. Because the sliding mode controller of the DFIG's flux is robust to external disturbances, so the power angle upheaval of the DFIG can be inhibited during a large disturbance and the drop of terminal voltage and rotor over current can be greatly weakened. Meanwhile the change of the DFIG power angle almost has no effect on the change of the SG power angle, which ensures the stability of the DFIG and SG hybrid transmission system during the grid fault. 


\subsection{Additional Control Strategy Of The Pitch Angle Of The DFIG Grid-Connected}

The power oscillation of the SG is mainly due to the fast recovery characteristics of the DFIG's power during the power grid fault. Through adjusting the pitch angle of the DFIG ${ }^{[12]}$, its output power can be reduced appropriately, the active output of the SG which runs in parallel with the DFIG will be increased and the oscillation of the output power will be reduced due to acceleration of the SG rotor. The stability of the system will be enhanced. In this article, error input signal of the pitch angle control is the difference between the actual output power of the DFIG's stator and the limit output power of the DFIG's stator during the grid fault. When the grid faults and the output power of the DFIG's stator exceeds its reference limited value, the additional control of the pitch angle starts to act. The active output of the DFIG is reduced to an appropriate value and then the additional control does not work when the system is in normal operation. The additional control block diagram of the pitch angle is shown in Figure 16 and its simulation model is shown in Figure 17. In this paper, the change rate of the pitch angle is limited to $\pm 10^{\circ}$ per second in order to achieve a rapid adjustment of the output power of the DFIG during the fault.

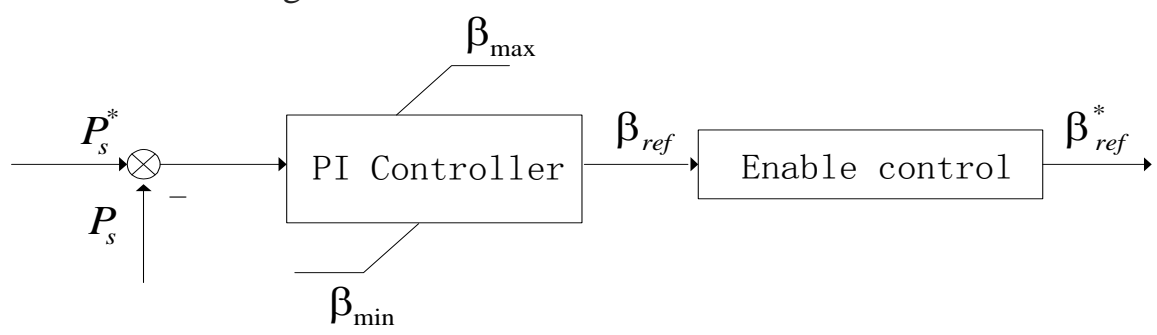

Figure 16: The Control Block of the Pitch Angle of the DFIG

In figure 16, the function expression of the enable control links is:

$$
\beta_{r e f}^{*}=\beta_{r e f} \operatorname{sgn}\left(\left|P_{s}^{*}-P_{s}\right|\right)
$$

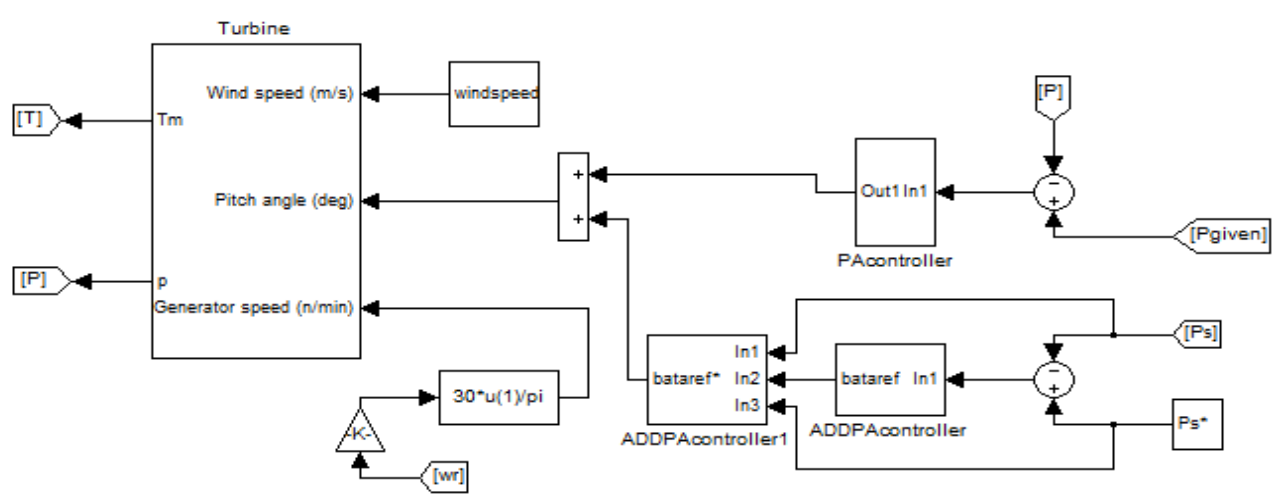

Figure 17: The Control Simulation Model of the Pitch Angle of the DFIG

\section{4 .The Grid-Connected DFIG Optimization Control Simulation}

In order to verify the proposed effectiveness of the terminal sliding mode control method of the DFIG power angle, a simulation schematic of the power-flux double-loop control system of the DFIG is established by using the simulation software the Power System of the Matlab/Simulink's Toolbox, which is shown in Figure 18 and its 
Matlab/Simulink simulation model is shown in Figure 19. It should be noted that in the simulation model the converter of this chapter is still using the average voltage model. The main model parameters of the doubly-fed induction generator and the synchronous generator are:

The equivalent parameters of the doubly-fed induction generator and the synchronous generator are the same with 2.1.

Network parameters:

$$
X_{T 1}=X_{T 2}=j 52.6 \Omega, \quad Z_{1}=Z_{2}=(15+j 112.7) .
$$

The main parameters of the sliding surface:

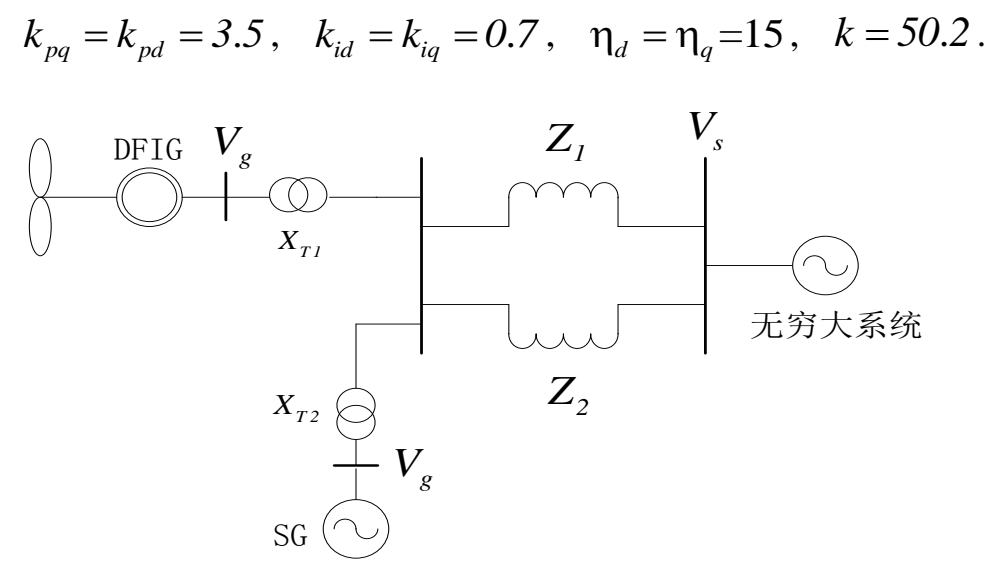

Figure 18: The Structure of the Wind \& Fire Hybrid Transmission System

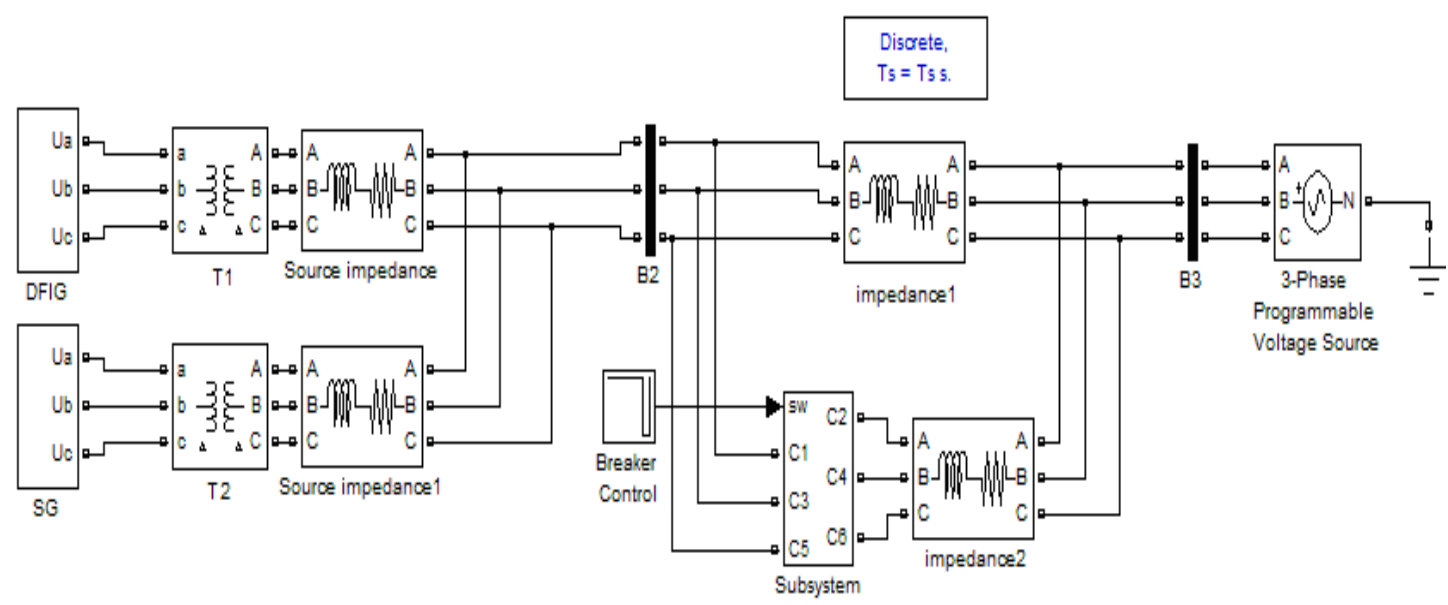

Figure 19: The Simulation Model of the "Wind \& Fire" Hybrid Transmission

Grid fault set: when $t=1 \mathrm{~s}$, one back of the double circuit transmission line (Z1 or Z2) is disconnected due to a short circuit fault trip, when $t=1.2 \mathrm{~s}$, reclosing successfully and the line is back to normal power supply.

Figures 20 and 21 show that the power angle of the DFIG just changes the $15^{\circ}$ during the grid fault by using the modified terminal sliding mode excitation control proposed by this paper. However, the power angle of the doubly fed induction generator has a "mutation" and its maximum can reach $190^{\circ}$ with conventional excitation control. Then the terminal voltage of the DFIG also appears in two distinct variations. Adopting the 
improved terminal sliding mode excitation control proposed by this paper, the drop of the terminal voltage is only $100 \mathrm{~V}$ and soon returns to the initial value. However, with the conventional excitation control, the DFIG's terminal voltage drops to $150 \mathrm{~V}$ and its recovery time is longer. As can be seen from the above analysis, by using the control method in this paper, the anti-interference ability of the DFIG's power angle is much better than the immunity of the DFIG's power angle under the conventional control. During a fault, the "mutation" feature can be effectively controlled and a variable ratio of the power angle which is caused by the drop of terminal voltage is also greatly reduced. Based on the above analysis, using the power angle PI terminal sliding mode control strategy, on the one hand effectively inhibits the "mutation" feature of the DFIG power angle to change and the amplitude greatly reduces, on the other hand the magnitude of terminal voltage drop has also been a significant improvements, providing a theoretical reference for improving DFIG LVRT capability.

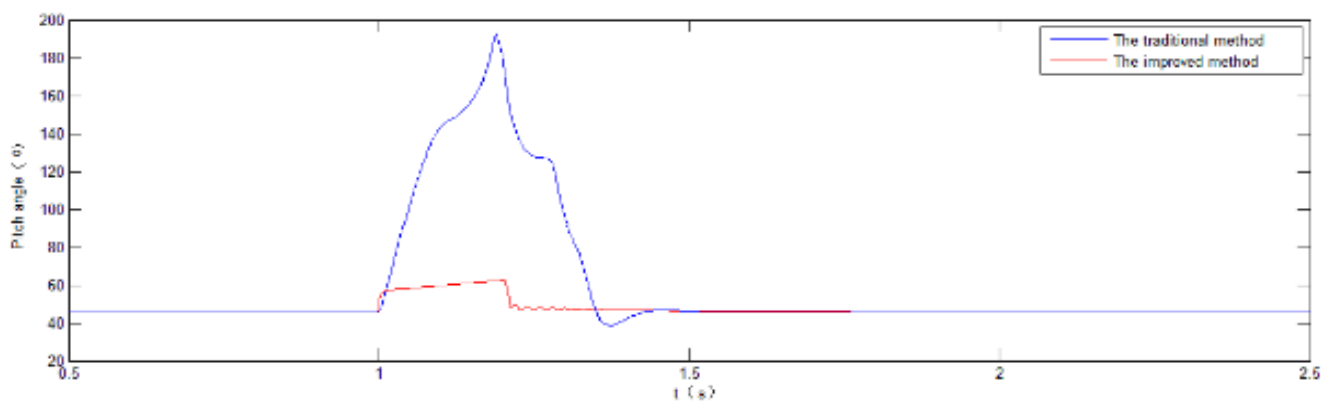

Figure 20: Comparison Chart of Control Performance of the DFIG Power Angle

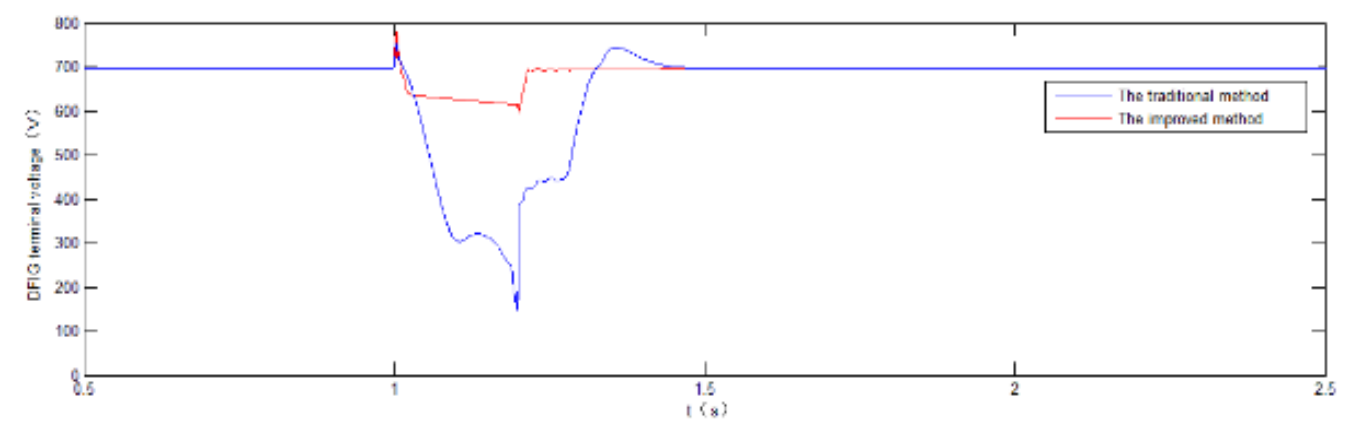

\section{Figure 21: Comparison Chart of Control Performance of the DFIG Terminal Voltage}

Figure 22 shows the response curve of the rotor current of the DFIG with the proposed control strategy by this paper. As can be seen from the figure, the excessive drop of the terminal voltage has been effectively prevented owing to the power angle of the DFIG having been well controlled and thus the over-current phenomenon of the rotor has been improved significantly also. 


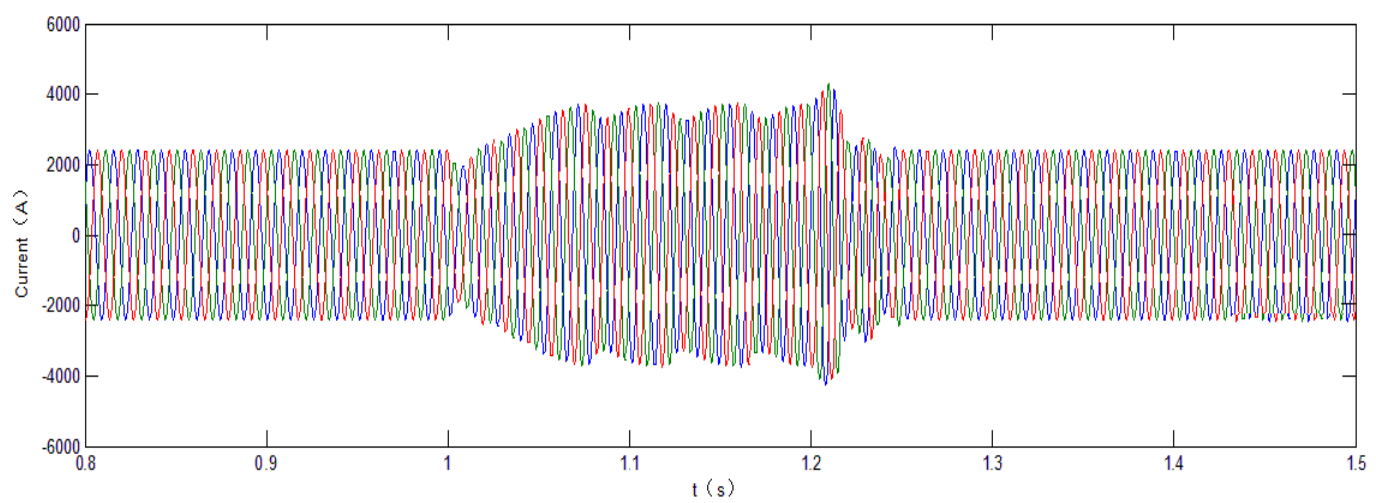

Figure 22: The Control Effect of Map of the DFIG Rotor Current

Figure 23 is the transient response curve of the SG's power angle in the "Wind \& Fire" hybrid transmission system. As can be seen from the figure, with the improved control strategy in the paper, the influence of the DFIG impacting on the power angle of the neighboring synchronous generator changes from the original "pulled" into the role of the "blocking" effect. Compared to traditional control methods, swing amplitude of the SG power angle is greatly reduced and the swing time is significantly shorter and this improves the ability to resist disturbances of the power grid and enhances the stability of the system.

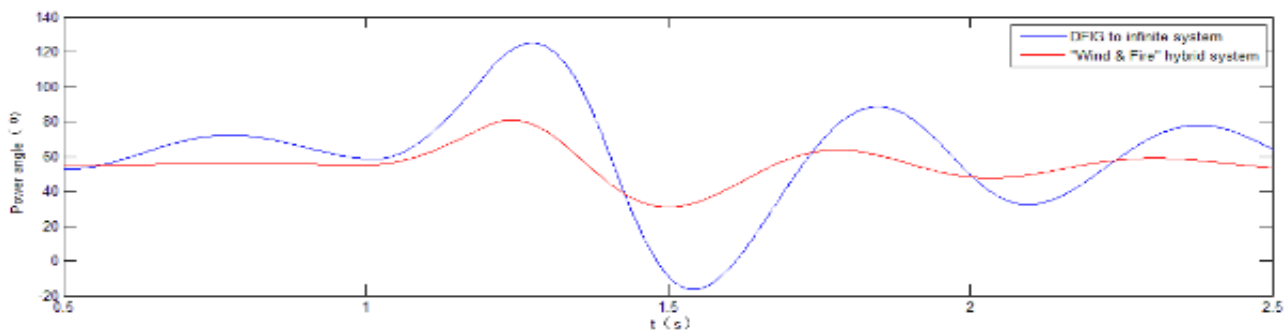

\section{Figure 23: Effect Comparison Chart Of The SG Power Angle Under Different Control Strategies}

Figures 24 and 25 respectively are the curves of the DFIG's pitch angle and the curve of the SG's rotor speed around the failure of the "wind \& fire" hybrid Transmission System. As can be seen from the figure, using the improved control strategy in this paper, when the power fails, by adjusting the pitch angle of the DFIG and increasing properly the active power output of the adjacent synchronous generator, the time of the swing of the SG's rotor speed can be significantly reduced and the stability of the system can be enhanced also.

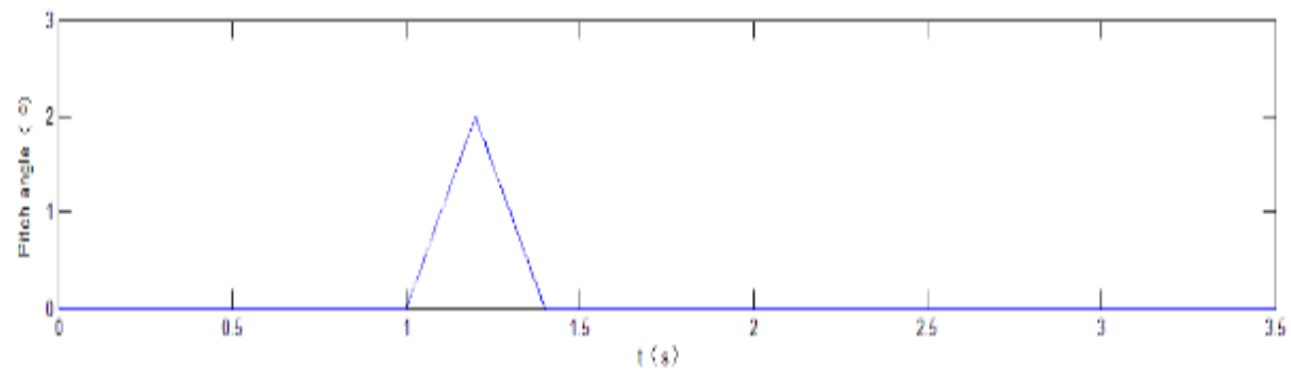

Figure 24: Curve Of The Pitch Angle Of The DFIG Before And After The Fault 


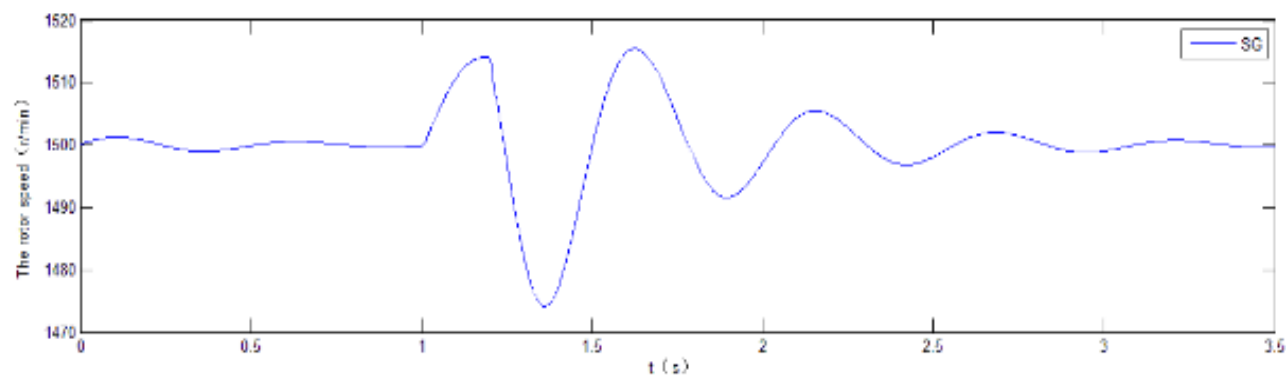

Figure 25: Speed Curve of the Sg Rotor under Improved Control Strategies

\section{Conclusions}

This paper mainly takes the DFIG grid-connected as the research object and puts forward to the joint optimization control strategy of the converter and the pitch angle in order to improve transient stability of the "Wind \& Fire" hybrid transmission system. On the one hand the control strategy reduces the disturbance of the grid fault on the doubly fed induction generator itself, on the other hand improves the stability of the power angle and the rotor speed of the synchronous generator and the anti-disturbance performance of the system. Simulation results show that, compared with the conventional PI control method, the joint optimization control strategy of the converter and the pitch angle mentioned in this paper can make the control of the wind power become more adaptability and stability, which has great significance for improving the network quality of the wind power generation system.

\section{Acknowledgements}

The work was supported by the scientific research fund of the NCWU for the high level talents project and the science and technology plan project of Zhengzhou City (43204-522).

\section{References}

[1] M. V. A. Nunes, J. A. P. Lopes, H. H. Zurn, U. H. Bezerra, and R. G. Almeida, "Influence of the variable-speed wind generators in transient stability margin of the conventional generators integrated in electrical grids", IEEE Trans. Energy Covers, vol. 19, no. 4, (2004).

[2] Eduard Muljadi, C. P. Butterfield and Brian Parsons, "Effect of variable speed wind turbine generator on stability of a weak grid", IEEE Transcations of Energy Conversion, vol. 22, no. 1, (2007).

[3] J. G. Slootweg and W.L. Kling, "Impact of large scale wind power generation on power system oscillations", Electric Power System Research, vol. 67, no. 1, (2003).

[4] R.D. Fernandez, R.J. Mantz and P.E. Battaiotto, "Impact of wind farms on a power system", An eigenvalue analysis approach, Renewable Energy, vol. 32, no. 10, (2007).

[5] Y. N. Chi, W. S. Wang and Y. H. Liu, "The impact of large scale wind farm on the transient stability of the power system", Automation of electric power systems, vol. 30, no. 15, (2006).

[6] X. L. Huang and Z. R. Liu, "Impact of power system integrated with large capacity of variable speed constant frequency wind turbines", TRANSACTION OF CHINA ELECTROTECHNICAL SOCIETY, vol. 25, no. 4, (2010).

[7] Y. X. Yu and L. Y. Chen, "Security and stability of the power system", Science Press, Beijing, (1988).

[8] Z. H. Hao, Y. X. Yu and Y. Zeng, "Transient performance of DFIG power angle in wind farm and it's control strategy", Electric Power Automation Equipment, vol. 31, no. 2, (2011).

[9] Y. F. Ren and Z. Q. An, "Flexible Grid connected operation and control of the double-fed wind turbine generator", Mechanical Industry Press, Beijing, (2011).

[10] Z. M. Chen, Z. Y. Wang and J. G. Zhang, "The Control Theory and Applications of Sliding Mode Variable Structure", Mechanical Industry Press, Beijing, (2012).

[11] M. M. Zhou and S. H. Li, "Composite control for cutting-in control of variable speed constant frequency doubly fed wind power generator", Journal of southeast university, vol. 42, no.1, (2012).

[12] J. H. Liu, Y. G. Lv and D. P. Xu, "The design and simulation of wind turbine's pitch robust controller", COMPUTER SIMULATION, vol. 27, no. 3, (2010). 


\section{Authors}

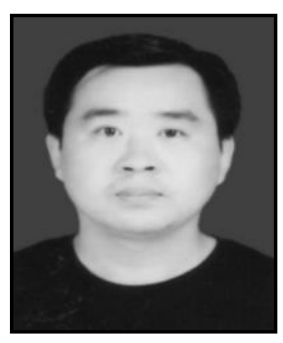

Xin Yu Liu was born on January 24, 1976. He is an associate professor and master tutor in North China University of Water Resources and Electric Power. He received his Ph. D degree in 2013 from Zhengzhou University, China. His main research interests include new energy power generation and smart grid.

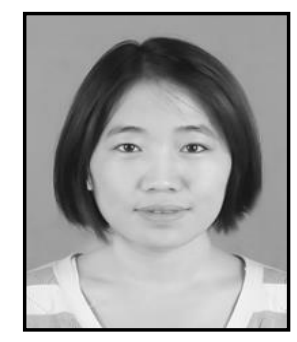

Hui Li Yang was born on March 16, 1989. She is a master of North China University of Water Resources and Electric Power. She mainly study on the control strategy of the inverter with the doubly fed wind power generation system.

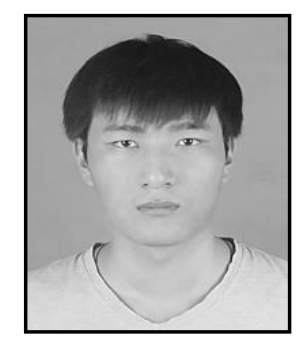

Ke Bai was born on March 21, 1989. He is a master of North China University of Water Resources and Electric Power. His research direction is the control technology of the low voltage ride through under the large-scale wind farms. 